\title{
NEW NAME FOR THE EXTINCT GENUS MESAGYRTES PONOMARENKO (COLEOPTERA: SILPHIDAE S.L.)
}

\author{
By Alfred F. Newton, JR. \\ Museum of Comparative Zoology \\ Harvard University, Cambridge, Mass. 02138
}

Mesagyrtes communis Ponomarenko, a new beetle genus and species attributed to Silphidae, has recently been described from fossil-bearing beds of Jurassic age from the locality of Novospassk, USSR (Arnoldi et al., 1977: 117). Unfortunately the generic name is preoccupied by Mesagyrtes Broun (1895: 95), proposed for a Recent New Zealand species originally placed in Silphidae; this genus is now considered a subgenus of the genus Colon Herbst of the family Leiodidae (Szymczakowski 1964).

I have brought the homonymy to the attention of Dr. Ponomarenko, who has kindly allowed me to propose a replacement name for use in publications on the family Silphidae now in preparation. Accordingly, I propose Mesecanus, new name, to replace Mesagyrtes Ponomarenko (not Broun). The new name alludes to the resemblance in habitus between the extinct genus and the Recent agyrtine silphid genus Ecanus Stephens.

\section{Literature Cited}

Arnoldi, L. V., V. V. Zherikhin, L. M. Nikritin and A. G. Ponomarenko

1977. "Mesozoic Coleoptera" [in Russian]. Trudi Paleont. Inst. Akad. Nauk SSSR 161, 204 pp.

Broun, T.

1895. Descriptions of new Coleoptera from New Zealand. AnN. Mag. Nat. Hist. (6)15: 67-88.

SZYMCZAKOWSKI, W.

1964. Révision des Colonidae (Coleoptera) des régions orientale et australienne. Acta Zool. Cracov. 9(8): 1 E59.

lienne. Acta Zool. Cracov. 9(8): 1-59. 

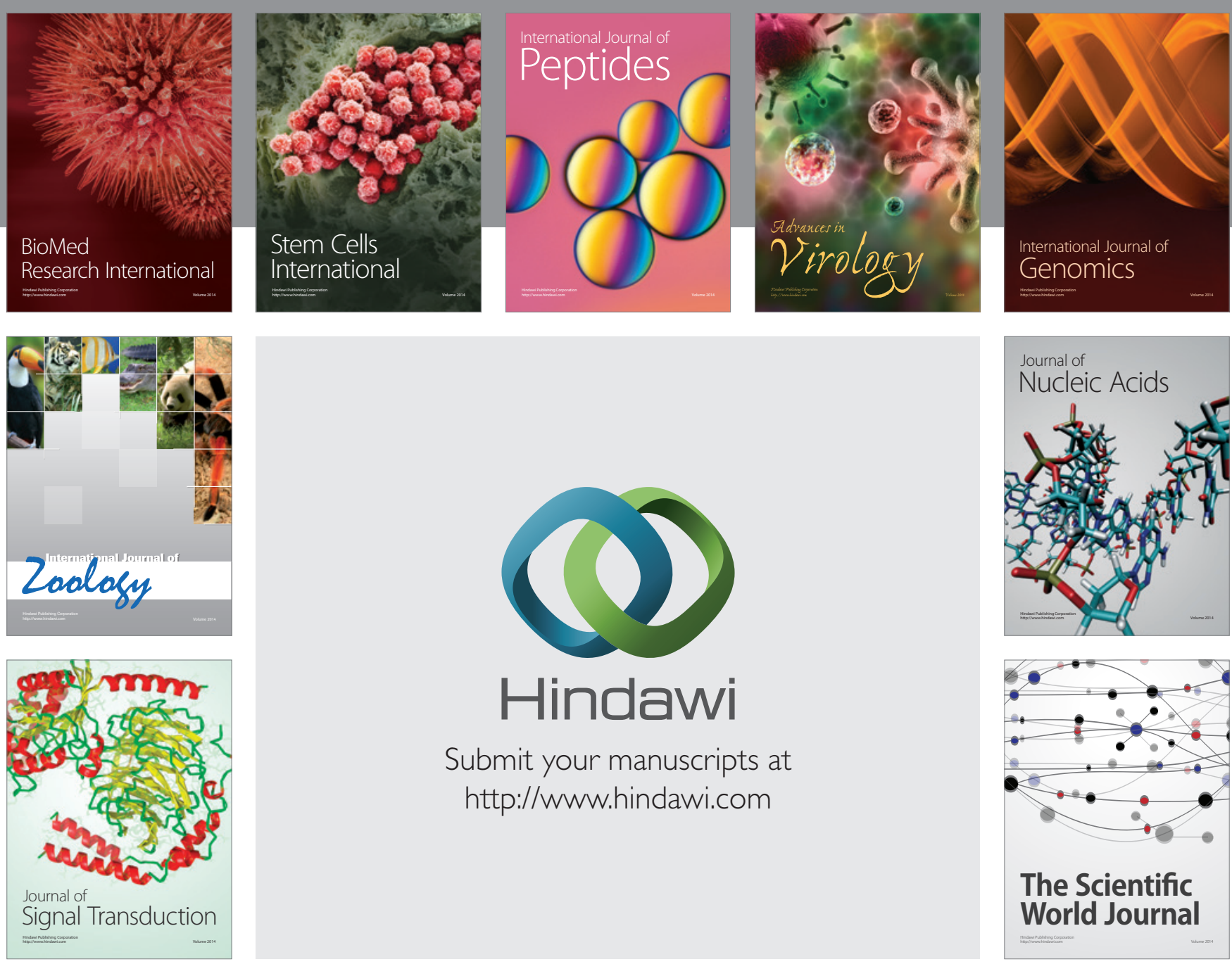

Submit your manuscripts at

http://www.hindawi.com
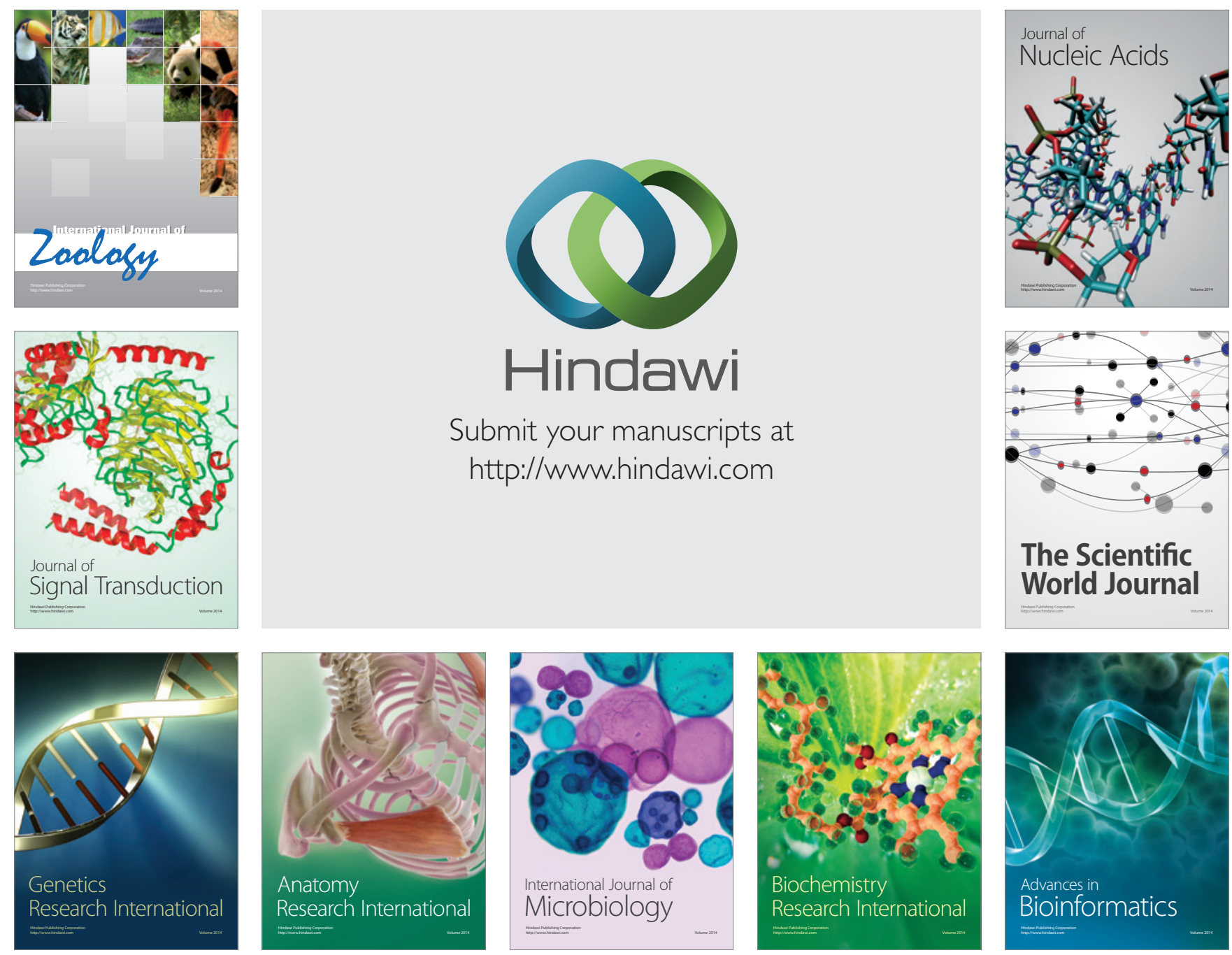

The Scientific World Journal
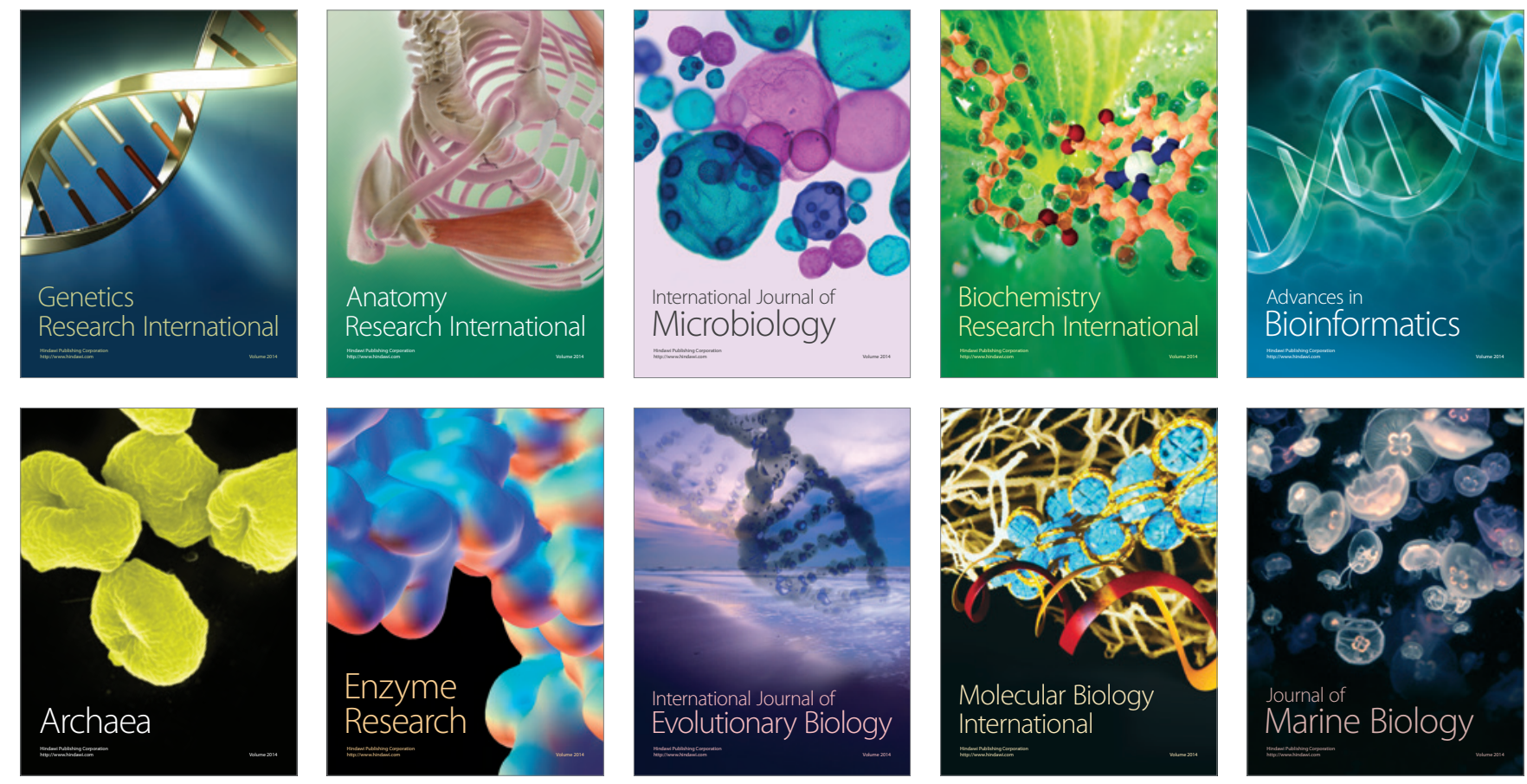